\title{
Normocalcaemic primary hyperparathyroidism: a pragmatic approach
}

\author{
Feaz Babwah, Harit N Buch
}

Wolverhampton Endocrine and Diabetes Unit, New Cross Hospital, Wolverhampton, UK

\section{Correspondence to}

Dr Harit N Buch; harit.buch@ nhs.net

Received 21 September 2017 Revised 12 January 2018 Accepted 13 January 2018 Published Online First 3 February 2018
Check for updates

To cite: Babwah F Buch HN. J Clin Pathol 2018:71:291-297.

\section{ABSTRACT}

It is well recognised that over the past three to four decades the incidence of asymptomatic primary hyperparathyroidism has increased significantly. However, more recently this pattern has further evolved into a presentation with normocalcaemia and raised parathyroid hormone (PTH) level without the presence of a recognised stimulus for its rise, in the form of vitamin $D$ deficiency or renal impairment. A diagnostic label of normocalcaemic hyperparathyroidism (NPHPT) has been given to this phenotype and in most such individuals, the initial PTH measurement is driven by the presence of metabolic bone disease. The reported prevalence, degree of end-organ involvement and the rate of progression vary considerably and are related to patients studied and the biochemical cut-offs used in its definition. A majority of patients are diagnosed during assessment of metabolic bone disease of varying degrees. Once the diagnosis is confirmed by excluding confounding factors, the patient should undergo full assessment of end-organ involvement, which is the main determinant of further therapeutic decisions. Surgery, with prior localisation, is considered in patients with significant end-organ involvement in keeping with the guidance for hypercalcaemic patients. If a patient does not meet these criteria, annual clinical and biochemical surveillance is recommended to identify progression to hypercalcaemia or worsening end-organ involvement. It is less clear if patients identified during 'routine' requests for evaluation of unrelated symptoms require similar close monitoring. In conclusion, in this review on NPHPT we focus on its definition, planning of further investigations, selection of patients for intervention and devising an appropriate follow-up strategy.

\section{BACKGROUND}

Over the past four to five decades, since the advent of multichannel autoanalysers, in a vast majority of patients, primary hyperparathyroidism has been diagnosed as a serendipitously discovered asymptomatic condition, when serum calcium is measured for unrelated reasons. It is now one of the most common endocrine disorders and between 1995 and 2010 its prevalence rose from 76 to 233 per 100000 women. ${ }^{1}$ Despite its incidental discovery, bone mass is typically reduced at the distal one-third of radius, a site that is enriched in cortical bone. ${ }^{2}$ Diagnostic workup and management strategy of this asymptomatic cohort has been the subject of four international workshops and is now better understood.

More recently, a newer clinical presentation of primary hyperparathyroidism has aroused considerable interest. It has been given the label of normocalcaemic primary hyperparathyroidism (NPHPT) and was initially described by Wills et al as a variant of primary hyperparathyroidism. ${ }^{3}$ Patients have normal concentration of total and ionised serum calcium with raised level of parathyroid hormone (PTH). In most such individuals, the initial PTH measurement is driven by the presence of metabolic bone disease or renal stones, which allows the identification of what is believed to be a previously unrecognised stage of the condition. Since its formal recognition in 2008, during the third international workshop on asymptomatic primary hyperparathyroidism, ${ }^{4}$ several studies have been published although there is a lack of uniformity in patient selection and cut-off values used to define the condition.

\section{DEFINITION}

NPHPT is defined by a raised PTH concentration in the presence of consistently normal total and ionised calcium levels, after excluding vitamin D deficiency, renal impairment, primary hypercalciuria, calcium malabsorption and the use of drugs that can potentially elevate PTH level. ${ }^{56}$ A significant proportion of patients who have high PTH in the presence of normocalcaemia have vitamin D deficiency or chronic kidney disease and it is essential to exclude these and other confounders to confirm the presence of NPHPT. ${ }^{6}$ Common drugs which may cause a raised PTH include thiazides, lithium, anticonvulsants, bisphosphonates and denosumab. ${ }^{6-8}$

\section{PATHOPHYSIOLOGY}

A commonly held hypothesis is that normocalcaemic and hypercalcaemic primary hyperparathyroidism (NPHPT and HPHPT, respectively) represent a bimodal sequence of onset of the same disorder. ${ }^{9}$ During the first phase, PTH concentration is elevated but normocalcaemia is maintained representing the 'subclinical' phase of the condition similar to that recognised for several other endocrine conditions. The second phase is the one that has traditionally been recognised by the detection of hypercalcaemia. The hypothesis that NPHPT represents an earlier stage of HPHPT is favoured by the lower PTH secretion $(75 \pm 19$ vs $93 \pm 49 \mathrm{pg} /$ $\mathrm{mL}, \mathrm{P}<0.001)$ and lower mass of adenomatous cells (229 vs $500 \mathrm{mg}, \mathrm{P}<0.05)$ in the former cohort of patients. ${ }^{10}$ It is further supported by the observation that in some patients NPHPT progresses to HPHPT $^{6811}$

Maruani et al explored another explanation by comparing patients with NPHPT and HPHPT 
Table 1 Prevalence and natural history of NPHPT

\begin{tabular}{|c|c|c|c|c|c|}
\hline Study & Patient cohort & $\begin{array}{l}\text { Vitamin D cut- } \\
\text { off ( } \mathrm{nmol} / \mathrm{L})\end{array}$ & $\begin{array}{l}\text { eGFR cut-off (mL/ } \\
\min )\end{array}$ & $\begin{array}{l}\text { NPHPT } \\
\text { prevalence (\%) }\end{array}$ & Natural history \\
\hline \multicolumn{6}{|c|}{ Population - based studies on asymptomatic patients } \\
\hline $\begin{array}{l}\text { Kontogeorgos et al }{ }^{14} \text { (WHO } \\
\text { MONICA, Sweden) }\end{array}$ & $\begin{array}{l}\text { General population aged } 25-64 \text { years } \\
(n=608)\end{array}$ & $>50$ & Not provided & 11.0 & $\begin{array}{l}\text { One person progressed to hypercalcaemia } \\
\text { None developed end-organ involvement (13- } \\
\text { year follow-up) }\end{array}$ \\
\hline $\begin{array}{l}\text { Lundgren et } a l^{1516} \\
\text { (Sweden) }\end{array}$ & Postmenopausal women $(n=5202)$ & Not excluded & $\begin{array}{l}\text { Not provided (serum } \\
\mathrm{Cr}>150 \mu \mathrm{mol} / \mathrm{L})\end{array}$ & 0.5 & $\begin{array}{l}\text { When reassessed at } 8.9 \text { years there was a } \\
\text { similar prevalence of NPHPT } \\
\text { Serum calcium increased by } 0.04 \pm 0.10 \mathrm{mmol} / \mathrm{L}\end{array}$ \\
\hline $\begin{array}{l}\text { Cusano et al } 1^{17} \\
\text { (MrOS, USA) }\end{array}$ & $\begin{array}{l}\text { Unselected community-dwelling men } \\
\text { aged } \geq 65 \text { years }(n=2364)\end{array}$ & $>50$ & $>60$ & 0.4 & Not followed-up \\
\hline $\begin{array}{l}\text { Cusano et a }\left.\right|^{17} \\
\text { (DHS, USA) }\end{array}$ & $\begin{array}{l}\text { General population aged } 18-65 \text { years } \\
(n=3450)\end{array}$ & $>50$ & $>60$ & 3.1 & $\begin{array}{l}\text { one person progressed to hypercalcaemia } \\
\text { None developed end-organ involvement } \\
29 \text { patients no longer met the criteria for } \\
\text { NPHPT at follow-up (8years) }\end{array}$ \\
\hline García-Martín et al ${ }^{18}$ (Spain) & Postmenopausal women $(n=100)$ & $>75$ & $>60$ & 6.0 & No progression (1-year follow-up) \\
\hline $\begin{array}{l}\text { Berger et al }{ }^{19} \\
\text { (CaMos, Canada) }\end{array}$ & $\begin{array}{l}\text { General population aged } 31- \\
97(n=1871)\end{array}$ & $>50$ & Not excluded & 16.7 & Not followed-up \\
\hline $\begin{array}{l}\text { Rejnmark et a } \beta^{38} \text { (DOPS, } \\
\text { Denmark) }\end{array}$ & Postmenopausal women $(n=2016)$ & Not excluded & $>60$ & 17.0 & $\begin{array}{l}\text { One person progressed to hypercalcaemia } \\
\text { (16-year follow-up) }\end{array}$ \\
\hline \multicolumn{6}{|c|}{ Referral population of high-risk patients* } \\
\hline $\begin{array}{l}\text { Lowe et al } \\
\text { (USA) }\end{array}$ & $\begin{array}{l}\text { Referred patients to metabolic bone } \\
\text { unit aged } 32-78 \text { years (NPHPT, } n=37 \text { ) }\end{array}$ & $>50$ & $>40$ & & $\begin{array}{l}\text { 19\% progressed to hypercalcaemia } 40 \% \\
\text { developed further end-organ involvement } \\
\text { (mean follow-up of } 3.1 \pm 0.3 \text { years) }\end{array}$ \\
\hline Maruani et $a l^{10}$ (France) & $\begin{array}{l}\text { Referred patients aged } 55 \pm 11 \text { years } \\
\text { to metabolic unit }(n=178)\end{array}$ & $>15$ & $>50$ & 19.1 & Data on progression not available \\
\hline $\begin{array}{l}\text { Šiprová et al } \\
\text { (Czech Republic) }\end{array}$ & $\begin{array}{l}\text { Referred patients aged } 26-85 \text { years } \\
\text { with suspected PHPT } \\
\text { (NPHPT, } n=187 \text { ) }\end{array}$ & $>50$ & Not provided & & $\begin{array}{l}19 \% \text { progressed to hypercalcaemia (6-year } \\
\text { follow-up—most progressed within } 2 \text { years) }\end{array}$ \\
\hline $\begin{array}{l}\text { Tordjman et al }{ }^{13} \\
\text { (Israel) }\end{array}$ & $\begin{array}{l}\text { Referred patients aged } \\
60.5 \pm 10.5 \text { years with suspected PHPT } \\
\text { (NPHPT, } n=32 \text { ) }\end{array}$ & $>50$ & Not provided & & $\begin{array}{l}12 \text { required surgery } \\
\text { No progression in the rest } \\
\text { (mean follow-up of } 4.1 \pm 3 \text { years) }\end{array}$ \\
\hline $\begin{array}{l}\text { Marques et } a l^{21} \\
\text { (Brazil) }\end{array}$ & $\begin{array}{l}\text { Referred women aged } \\
62.4 \pm 10.5 \text { years to exclude } \\
\text { osteoporosis }(n=156)\end{array}$ & $>75$ & $>40$ & 8.9 & Data on progression not available \\
\hline
\end{tabular}

*Patients who are at a higher risk of metabolic bone disease or already have adverse bone and renal outcomes like osteoporosis, fragility fractures or renal calculi. eGFR, estimated glomerular filtration rate; NPHPT, normocalcaemic hyperparathyroidism; PHPT, primary hyperparathyroidism.

for renal calcium and phosphate handling and bone turnover makers. Patients with NPHPT had lower fasting urine calcium excretion and tubular reabsorption, higher value of renal phosphate threshold and lower values of markers of bone turnover. Based on these findings they proposed that in patients with NPHPT, maintenance of normocalcaemia is a manifestation of resistance of renal tubules and the skeleton to the effects of PTH, possibly linked to the protective impact of oestrogen. ${ }^{10}$ However, the progression of NPHPT to HPHPT and its diagnosis during postmenopausal age group do not support this hypothesis. Their findings have not been reproduced and the concept of biphasic onset is now widely accepted.

\section{EPIDEMIOLOGY AND NATURAL HISTORY}

The data on the epidemiology and natural history of NPHPT is limited and conflicting and this has hindered formal recommendations to be made on its work-up and management. Although no formal age and gender distribution data is available, NPHPT is more commonly seen in women of postmenopausal age group, as is HPHPT. ${ }^{511} 12$ A wide range of prevalence figures and rates of progression are reported due to variations in the criteria used to exclude secondary hyperparathyroidism and in the selection of the study population as summarised in table 1 .

Most patients in clinical practice are identified during evaluation of high-risk groups, that is, those who have adverse bone and renal outcomes like osteoporosis, fragility fractures or renal calculi or are at a higher risk of developing these. As would be expected, studies undertaken on such high-risk cohorts report higher prevalence figures and rates of progression. ${ }^{6} 101113 \mathrm{In}$ the Columbia cohort of 37 patients with NPHPT referred to a tertiary bone unit, $40 \%$ individuals developed new features of primary hyperparathyroidism. During a follow-up of $3.1 \pm 0.3$ years (mean $\pm \mathrm{SD}$ ), seven individuals developed hypercalcaemia, one had a new fracture, four had new osteoporosis, one developed renal stones and two patients had significant hypercalciuria. Patients who showed progression were older, had higher baseline serum calcium level $(2.4 \pm 0.05$ vs $2.3 \pm 0.02 \mathrm{mmol} / \mathrm{L})$ and higher baseline urinary calcium excretion. Seven patients underwent successful parathyroidectomy leading to normalisation of PTH in all patients with operative findings of either a solitary adenoma or hyperplasia. ${ }^{6}$ Tordjman et al reported a series of 32 patients with NPHPT identified from their cohort of patients with primary hyperparathyroidism in the endocrine clinic. While 20 patients managed conservatively did not have any significant change in serum calcium level after a mean follow-up of $4.1 \pm 3$ years, 12 patients required surgery based on established metabolic bone disease and positive localisation studies. $^{13}$

However, the true prevalence of NPHPT is best assessed by studies undertaken on unselected cohorts which report a lower 
prevalence and rate of progression. ${ }^{14-18}$ A Swedish study on 608 individuals from a non-referral population reported a prevalence of $2 \%$ in 1995 which increased to $11 \%$ in 2007, with vitamin D deficiency and renal impairment appropriately excluded. After 13 years of follow-up only one patient progressed to hypercalcaemia and none had adverse bone, renal or cardiovascular outcomes. The authors suggest that the seemingly high prevalence at the time of the follow-up assessment may be secondary to confounding factors like increasing age, body mass index or changing vitamin D level irrespective of its absolute value. ${ }^{14} \mathrm{~A}$ recent review of two unselected community-dwelling cohorts from the USA by Cusano et al (The Osteoporotic Fractures in Men, MrOS and Dallas Heart Study, DHS) reported an even lower prevalence figures of $0.4 \%$ and $3.1 \%$, respectively. ${ }^{17} \mathrm{~A}$ prevalence of $16.7 \%$ was reported in a Canadian-based study of 1871 subjects from general population (CaMos), although vitamin $\mathrm{D}$ deficiency was not excluded. ${ }^{19}$ The above studies also highlight a disparity in the reported prevalence of NPHPT from Canada, USA and Europe.

On the basis of these studies on such varied patient groups, we can conclude that the prevalence of NPHPT in general population is low when strict criteria are used to exclude secondary hyperparathyroidism and other confounding influences. By contrast, when NPHPT is identified during assessment of patients with metabolic bone disease or renal stones, the rate of progression is high in untreated patients, indicating the need to assess such individuals for progressive rise in serum calcium and/or end-organ involvement during the initial evaluation and follow-up.

\section{CLINICAL AND LABORATORY EVALUATION}

There are no formal recommendations on how to investigate, manage and follow the patients identified with NPHPT. On the basis of our greater understanding over the past decade, the following three-step pragmatic approach is proposed for evaluation of NPHPT and is depicted diagrammatically in figure 1.

\section{Biochemical confirmation of NPHPT}

Persistent normocalcaemia

Biochemical diagnosis of NPHPT consists of demonstration of persistent normocalcaemia using serial ionised calcium or serum albumin-adjusted total calcium in the presence of an elevated $\mathrm{PTH}^{5}{ }^{6}$ Persistence of normocalcaemia distinguishes NPHPT from HPHPT where calcium can be intermittently elevated. ${ }^{20}$ One could hypothesise that the phase of intermittent hypercalcaemia may represent a transition stage between patients with normocalcaemia and hypercalcaemia.

The Proceedings of the Fourth International Workshop on the diagnosis of asymptomatic PHPT recommended that ionised calcium should be in the normal range. ${ }^{7}$ It represents the biologically active free fraction of calcium ${ }^{21}$ and remains the gold-standard measurement. It has specific benefits in the context of NPHPT where the albumin-adjusted value has been found to be misleadingly normal in patients with high-ionised calcium. $^{22}{ }^{23}$ Adjusted calcium can also be unreliable in low-albumin states. ${ }^{23}$ Maruani et $a l^{10}$ and Wade et $a l^{24}$ demonstrated significant discordance between ionised and total calcium and recommended the use of the former. However, point-of-care (POC) testing with blood gas analyzers used to obtain ionised calcium level is not widely available in an outpatient setting and its use is hindered by other barriers such as precision, standardisation, special sample management and high cost. ${ }^{22} 25$ In view of these constraints and in keeping with its use in multiple other

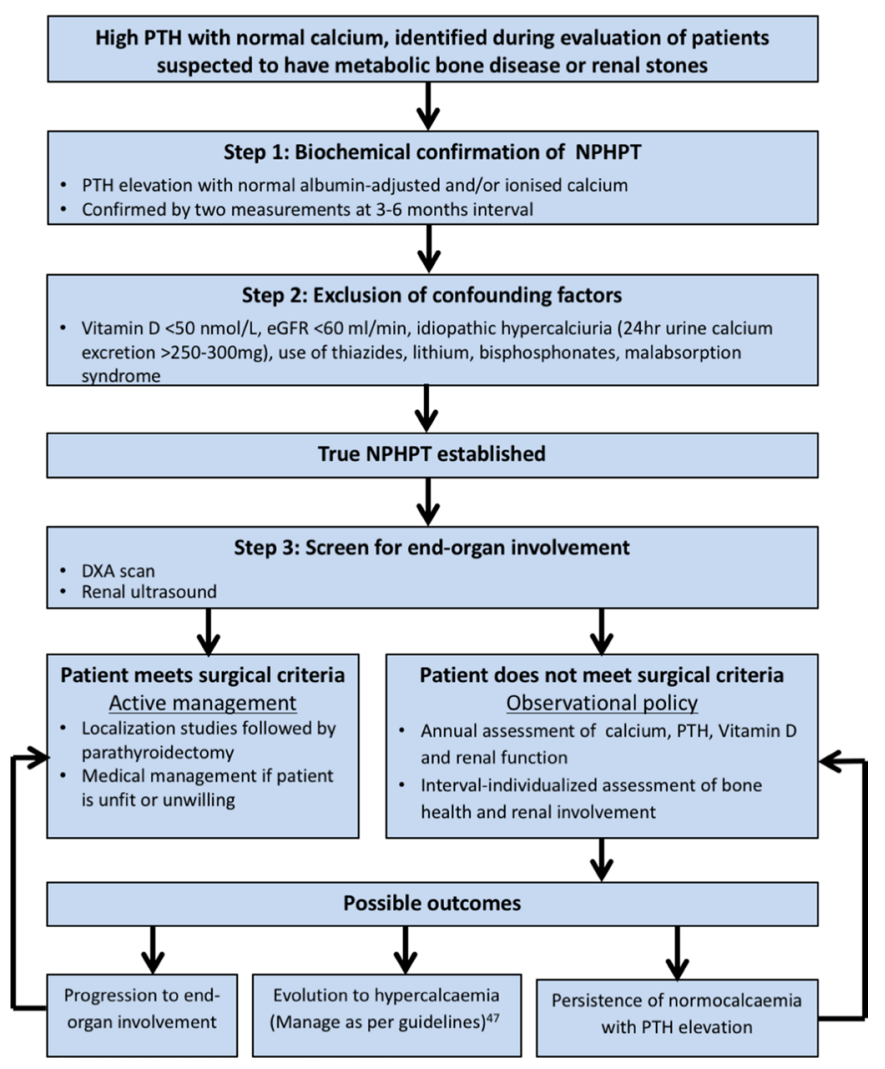

Figure 1 Proposed management plan for patients with NPHPT. DXA, dual-energy x-ray absorptiometry, NPHPT, normocalcaemic primary hyperparathyroidism; PTH, parathyroid hormone.

studies, ${ }^{6} 81314$ serum albumin-adjusted total calcium continues to be measured and reported in many UK centres. ${ }^{26}$ However, we would certainly recommend confirmation of normocalcaemia with ionised calcium estimation if the albumin-adjusted value remains close to the upper limit of reference range and in patients with low albumin.

\section{Raised PTH}

A persistently elevated PTH is a sine qua non of NPHPT and it is important to be aware of the potential problems in the measurement of PTH. The PTH immunoassay has evolved over the last 50 years. In an effort to reduce the cross-reactivity with PTH fragments the first generation single-site antibody immunoassay has been superseded by two-site immunometric second and third generation assays which measure 'intact PTH' and 'whole or complete PTH' respectively. ${ }^{7}$ There is, however, considerable variability between the different commercially available assays with no universally agreed cut-off for the upper-limit of normal. ${ }^{27} \mathrm{PTH}$ may also be influenced by ethnicity and age and like all immunoassays is subject to analytical interference from heterophilic antibodies. ${ }^{28}{ }^{29}$ In addition, chronic renal failure increases the level of circulating PTH fragments of varying sizes and can lead to a higher level of PTH especially with the use of intact PTH assay. ${ }^{27}$

The impact of these limitations in PTH measurement is not crucial in the diagnosis of HPHPT, as current PTH assays are capable of differentiating between PTH-driven and PTH-independent hypercalcaemia. ${ }^{28}$ They are however of greater concern in the diagnosis of NPHPT with a potential for patient misclassification and inappropriate patient management. It is widely accepted that a traceable reference method for PTH1-84 is 
urgently needed to harmonise PTH methodologies and thereby reduce the interassay variability which currently limits clinical and epidemiological applications of this assay particularly in NPHPT. $^{27}$

\section{Retesting}

Both calcium and PTH should be measured on at least two occasions 3-6 months apart to secure the diagnosis of NPHPT. ${ }^{20}$

\section{Exclusion of confounding factors}

The next crucial step in the diagnostic workup is a meticulous search for the presence of secondary hyperparathyroidism for which vitamin $\mathrm{D}$ deficiency is the the most common cause. ${ }^{30}$ There are several uncertainties about the relationship between the vitamin D status and PTH level. Over the past decade, different PTH assays have been used and the level of 25-hydroxy vitamin $\mathrm{D}$ at which the reference range of a particular assay has been derived is not clear. ${ }^{31}$ Moreover, the lower level of vitamin D at which PTH rises has not been established across all populations $s^{5}$ and several factors like ethnicity, dietary calcium and serum magnesium have been shown to have an impact on this relationship. ${ }^{32}$ However, it is generally agreed that the absolute level of 25-hydroxy vitamin D at which PTH begins to rise lies somewhere between 50 and $75 \mathrm{nmol} / \mathrm{L}(20 \text { and } 30 \mathrm{ng} / \mathrm{mL})^{8}$ and a value of $>50 \mathrm{nmol} / \mathrm{L}$ is widely accepted as being sufficient to meet the demands of the majority of patients and would allow the diagnosis of NPHPT to be made. Patients with a lower level should receive vitamin D replacement for at least 3 months, followed by PTH monitoring to exclude or confirm NPHPT, ${ }^{20}$ although in some cases it can take up to 6-12 months for PTH level to normalise. ${ }^{7}$ Less commonly vitamin D replacement may lead to unmasking of hypercalcaemia, thereby making the diagnosis of HPHPT. ${ }^{572026}$ An interesting approach has been proposed by Harvey et al, who used serum calcium, PTH, vitamin $\mathrm{D}$ and age to create a four-dimensional nomogram. With the use of this nomogram in surgically treated patients, $100 \%$ of patients with HPHPT, 84\% with NPHPT and 54\% with HPHPT with normal PTH could be predicted. ${ }^{33}$

The other major confounding factor to consider is renal failure, which is a well-known cause of secondary and tertiary hyperparathyroidism. There is an inverse relationship between PTH and glomerular filtration rate (GFR) as demonstrated by Martínez Diaz-Guerra et al. ${ }^{20} \mathrm{PTH}$ has been shown to rise with a fall in estimated GFR to $<60 \mathrm{~mL} / \mathrm{min}$ in large population surveys and a value of $>60 \mathrm{~mL} / \mathrm{min}$ would support the diagnosis of NPHPT despite the difficulty in ascertaining the cut-off in individual patients. ${ }^{720}$ Some studies have used an exclusion criterion of $<40 \mathrm{~mL} / \mathrm{min},{ }^{5621}$ but this seems too generous.

Primary or idiopathic hypercalciuria (IH) should be excluded. $\mathrm{IH}$ is the the most common metabolic abnormality in patients with calcium kidney stones and is defined as a 24-hour urine calcium excretion $>6.2 \mathrm{mmol}(250 \mathrm{mg})$ in women and $>7.5 \mathrm{mmol}$ $(300 \mathrm{mg})$ in men. ${ }^{34}$ Serum calcium is normal in most patients with $\mathrm{IH}$ but can be low-normal with a rise in PTH level resulting in a biochemical picture similar to NPHPT. However, in NPHPT the degree of hypercalciuria is milder and serum calcium is high to normal. Thiazide challenge test can be used to exclude $\mathrm{IH}$ although is rarely required. ${ }^{35}$

Other causes of elevated PTH level to be considered include the use of medications such as thiazide diuretics, lithium, anticonvulsants and bisphosphonates. ${ }^{5}$ Denosumab, which is increasingly being used in the management of osteoporosis, has also been implicated. ${ }^{7}$ Malabsorptive gastrointestinal conditions can also result in this biochemical picture. Hypomagnesaemia should be excluded. ${ }^{20}$

\section{Assessment of end-organ involvement}

Once a patient is identified as having NPHPT, the next step is to determine if they have end-organ involvement, as is the case with asymptomatic HPHPT. One would expect NPHPT to be a mild condition but this is not necessarily the case. Several reports indicate that the prevalence of bone and renal involvement is either higher or similar to patients with hypercalcaemia. ${ }^{6} 112136$ In patients with established bone or renal involvement at the time of the diagnosis, assessment should focus on the likely impact of NPHPT on disease progression.

\section{Bone}

There has been a greater awareness of bone health during recent times which has led to an increase in targeted screening for osteoporosis and assessment of fracture risk. This has led to the increase in PTH measurement in patients who are deemed to be at a higher risk of metabolic bone disease on the basis of the known risk factors or a high Fracture Risk Assessment (FRAX) risk score. ${ }^{37}$ This process of PTH measurement was used when NPHPT was initially formally diagnosed in $2008^{4}$ and has also formed the basis of several subsequent studies. Not surprisingly a high rate of progressive bone involvement has been reported in such studies. Lowe et al reported a 57\% prevalence of osteoporosis and $11 \%$ fragility fracture rate in their cohort of 37 patients with NPHPT. After a median follow-up of 3 years, $43 \%$ of patients had a progressive decline in BMD at all sites and in a fifth of these the decline was $>10 \%$. There appeared to be no correlation between the level of PTH or baseline BMD and deterioration of bone health. ${ }^{6}$ In other studies undertaken on similar patient groups, the reported rate of progressive bone involvement has ranged between $15 \%$ and 36\%. ${ }^{13212436}$ However, the selection bias inherent in these studies makes it difficult to estimate the 'true' frequency of bone involvement in patients with NPHPT. In the WHO MONICA study on a randomly selected Swedish cohort from the general population, there was no impact on ultrasound attenuation values or fracture rate in patients with NPHPT as compared with those with normal PTH. ${ }^{14}$ The Danish Osteoporosis Prevention Study (DOPS, 1097 patients), a population-based prospective study, correlated PTH level in normocalcaemic postmenopausal women with long-term fracture risk. Patients with higher baseline PTH had lower bone mineral density and an increased fracture risk. However, this impact was only seen in patients whose vitamin $\mathrm{D}$ was $<80 \mathrm{nmol} / \mathrm{L}$ and higher level of vitamin D appeared to protect against the adverse bone outcomes associated with high PTH level. ${ }^{38}$

There is a lack of clarity about the pattern of bone involvement in patients with NPHPT. Lowe et al reported osteoporosis in NPHPT to commonly involve the lumbar spine (34\%) and hip (38\%), with no preferential bone loss at the distal one-third of radius ${ }^{6}$ unlike in patients with $\mathrm{HPHPT}^{5}$ Marques et al, however, demonstrated similar level $(28.5 \%)$ of osteoporosis at lumbar spine and distal radius. ${ }^{21}$ Charopoulos et al used high-resolution peripheral quantitative CT in 52 postmenopausal women with primary hyperparathyroidism. The bone mineral content and volumetric bone mineral density were reduced at cortical as well as cancellous sites in both NPHPT and HPHPT groups but the latter group demonstrated a greater reduction. ${ }^{39}$ Although catabolic effects on bone are present in all patients with primary hyperparathyroidism, markers of bone turnover and net bone calcium release are lower in the normocalcaemic group. ${ }^{10}$ 
This supports the end-organ tissue PTH resistance hypothesis proposed by Maruani et $a l^{10}$ but could also be explained by the relatively lower PTH level in patients with NPHPT.

\section{Renal}

The impact of NPHPT on the kidneys appears to be similar to that of patients with HPHPT, namely nephrolithiasis and nephrocalcinosis, with a wide variance in the reported figures for its prevalence. A retrospective analysis reported a similar prevalence of nephrolithiasis in NPHPT (18.2\%) and HPHPT (18.9\%). ${ }^{36}$ Maruani et $a l^{10}$ noted a prevalence as high as $35 \%$ and in other studies it has ranged from $4 \%$ to $28.6 \% .^{611} 21$ The presence of hypercalciuria in patients with HPHPT has been reported to be around $40 \% .{ }^{40} \mathrm{~A}$ similar but milder increase in 24-hour urinary calcium excretion has been observed in patients with NPHPT with the proposed mechanism being a relatively lower calcium reabsorption rate. ${ }^{10}$ However, there are no reports of its prevalence or its correlation with renal calculi formation. As in patients with HPHPT, it is not known why some patients with NPHPT form stones and in both these groups of patients the degree of calcium excretion is not a strong single predictor of calculi formation. There is also no evidence on the likelihood of progression of renal involvement with time or on the impact of parathyroid surgery.

\section{Cardiovascular}

The link between cardiovascular disease and primary hyperparathyroidism remains contentious. An epidemiological study from Rochester (USA) reported a lower than expected cardiovascular mortality in these patients. ${ }^{41}$ However, the Parathyroid Epidemiology and Audit Research Study (PEARS) ${ }^{42}$ as well as several Scandinavian studies ${ }^{43}$ have shown an increase in all-cause mortality, fatal and non-fatal cardiovascular events in patients with primary hyperparathyroidism. A number of risk factors and surrogate end-points have been proposed as mechanisms including hypertension, dyslipidaemia, insulin resistance, endothelial dysfunction and left ventricular hypertrophy.

Neither of these studies comment on whether NPHPT has a similar impact on cardiovascular outcomes. However, one cross-sectional, case-control study involving 25 patients with NPHPT, matched against a similar number of patients with HPHPT and healthy subjects demonstrated a higher prevalence of metabolic syndrome, glucose intolerance and hypertension among the NPHPT and HPHPT groups as compared with the control group. ${ }^{44}$ Another study on 18 subjects with NPHPT, found no difference in insulin resistance or glucose intolerance when assessed by oral glucose tolerance test (OGTT) and homeostasis model assessment for insulin resistance (HOMA-IR) when compared with matched control subjects. ${ }^{45}$ Two other studies have reported a higher prevalence of hypertension in patients with NPHPT compared with patients with a normal PTH. ${ }^{13} 46$

However, as there is no prospective data on cardiovascular outcomes in patients with NPHPT, ${ }^{47}$ further investigations to evaluate cardiovascular risk do not form part of the workup for patients identified with NPHPT and nor is parathyroid surgery recommended with a view to improving cardiovascular endpoints.

\section{MANAGEMENT STRATEGY AND FOLLOW-UP}

In the absence of sufficient data on its natural history, it is challenging for a clinician to formulate a management plan for an individual patient with a confirmed diagnosis of NPHPT.
Table 2 Indications for surgery in asymptomatic PHPT (2013) ${ }^{47}$

\begin{tabular}{|c|c|}
\hline \multicolumn{2}{|c|}{ Indications for surgery in asymptomatic PHPT } \\
\hline $\begin{array}{l}\text { Serum } \\
\text { calcium }\end{array}$ & $>0.25 \mathrm{mmol} / \mathrm{L}$ above the upper limit of normal \\
\hline Bone & $\begin{array}{l}\text { BMD by DXA: T-score (or Z-score if age }<50 \text { years) }<-2.5 \text { at lumbar spine, } \\
\text { total hip, femoral neck or distal } 1 / 3 \text { radius } \\
\text { Vertebral fracture by } x \text {-ray, CT, MRI or VFA* }\end{array}$ \\
\hline Renal & $\begin{array}{l}\text { Creatinine clearance }<60 \mathrm{~mL} / \mathrm{min} \dagger \\
24 \text { hours urine for calcium }>400 \mathrm{mg} / \text { day and increased stone risk by } \\
\text { biochemical analysis } t \\
\text { Presence of nephrolithiasis or nephrocalcinosis by } x \text {-ray, ultrasound or } \mathrm{CT}\end{array}$ \\
\hline Age & $<50$ years \\
\hline
\end{tabular}

Patients need to meet only one criterion for consideration of surgery.

${ }^{*}$ A history of fragility fracture at any site would define symptomatic PHPT and the patient would be automatically considered a surgical candidate.

tChronic kidney disease and hypercalciuria are not relevant as these patients strictly speaking do not have NPHPT. BMD, bone mineral density; DXA, dual-energy $x$-ray absorptiometry; NPHPT, normocalcaemic primary hyperparathyroidism; VFA, vertebral fracture assessment.

In clinical practice, in a vast majority of patients, the diagnosis of NPHPT is arrived at when calcium and PTH levels are requested during the evaluation of patients who have, or are at a higher risk of having, metabolic bone disease or have nephrolithiasis. A suggested management strategy for this cohort of patients is depicted in figure 1. Once the investigations for assessment of bone and renal involvement are completed, in the absence of hypercalcaemia, a decision can be made on whether surgery is indicated on the basis of the degree of end-organ involvement. The criteria used are the same as in patients with asymptomatic HPHPT as specified in the fourth international workshop (table 2). ${ }^{47} 48$

Patients in whom surgery is indicated, its suitability should be confirmed on the basis of factors such as age, frailty, comorbidities and patient preference. Localisation studies including ultrasonography and radionuclide scanning should be requested. In comparison to patients with HPHPT, a higher frequency of negative localisation studies and surgical failure has been reported. $^{24} 49$ This is likely to be related to the smaller size of the adenoma encountered in patients with NPHPT. Another less likely explanation is the greater frequency of multigland hyperplasia, reported in some studies. ${ }^{240}$ However, in these studies, conclusions were drawn from a small number of patients and there was a lack of clarity on how secondary hyperparathyroidism was excluded. Moreover, several other studies have reported the presence of a solitary parathyroid adenoma in a majority of patients studied. ${ }^{11} 2051$ Successful removal of an adenoma has been shown to normalise postoperative PTH level ${ }^{6}{ }^{13}$ which is the only biochemical criterion that can be used to indicate cure. BMD has been shown to improve as early as 1-2 years postparathyroidectomy in patients with both symptomatic HPHPT and NPHPT. $^{345253}$

Patients in whom the degree of bone or renal involvement is not significant enough to consider surgery, a structured observational policy can be adopted. This consists of annual monitoring of albumin-adjusted or ionised calcium, PTH, vitamin D and renal function. ${ }^{547}$ Reassessment of bone density and nephrolithiasis at 3-5 year intervals has been recommended, ${ }^{26}$ although it may be more practical to adopt an individualised approach guided by the baseline measurements and overall risk profile for progressive bone disease. A 3-yearly reassessment to examine the sequential change in the bone density would certainly be recommended for patients with osteopaenia ( $\mathrm{T}$ score between -1.0 
and -2.5 ), those with multiple risk factors for osteoporosis or those with a high FRAX score at baseline. There is no clear guidance on the need for monitoring of urinary calcium in NPHPT and we do not recommend this, as the degree of hypercalciuria is mild ${ }^{10}$ and is not likely to help in predicting nephrolithiasis. During this period, we suggest maintaining vitamin D level to $>50 \mathrm{nmol} / \mathrm{L}$ (and ideally $>75 \mathrm{nmol} / \mathrm{L}$ ). ${ }^{7}$ Occasionally, $\mathrm{PTH}$ may normalise and the patient would no longer fulfil the criteria for NPHPT. On the other hand, patients who demonstrate progression to hypercalcaemia or new onset of bone or renal complications would merit assessment for surgery as above.

Patients in whom surgery is indicated but is not undertaken because of comorbidities or patient preference, bisphosphonates can be considered. These agents have been proven to be effective in improving bone mineral density in short-term studies but there is no robust fracture data. ${ }^{4753}$ There is also no literature on the benefit of these or any other agents in patients with NPHPT. There is no role for cinacalcet therapy in lowering PTH levels or improving bone outcomes. While one small prospective randomised study reported a reduction in the number and size of renal stones with the use of cinacalcet in patients with NPHPT and $\mathrm{HPHPT}_{4}{ }^{40}$ a 5 -year multicentre randomised controlled trial showed that there was no effect on bone mineral density. ${ }^{54}$

More recently, clinicians are coming across patients with high PTH level without hypercalcaemia or end organ involvement, in whom the initial biochemical tests were requested to explain either unrelated symptoms or serendipitous finding of a parathyroid adenoma on imaging studies. Although a significant proportion of these patients have one or more of the recognised confounding factors and do not have NPHPT, a small cohort meets the criteria for the diagnosis and pose a management challenge to the clinician. The above-mentioned strategy for long-term follow-up may not be necessary for many of these patients who are often at a lower risk of end-organ involvement. We would recommend regular review only for those patients who are more likely to progress, that is, those with baseline albumin-adjusted calcium $\geq 2.4 \pm 0.05 \mathrm{mmol} / \mathrm{L} \quad(\mathrm{P}<0.01)^{6}$ or adverse risk profile for bone disease as described above. For the remaining patients, the same frequency of reassessment may not be required and the decision can be individualised on the basis of clinical and logistic factors. This approach is supported by several studies that have shown a low progression rate in similar patient groups (table 1). ${ }^{814} 18$

\section{FUTURE POSSIBILITIES}

Insufficient data on the natural history of NPHPT has led to a paucity of evidence-based recommendations on its management. More studies on large cohorts of patients followed up for a longer periods would certainly allow us to further standardise our approach to the management of this condition. On the diagnostic side, any future development that focuses the inconsistencies with PTH assays described above would be of significant benefit. Although traceable reference materials (eg, the WHO Recombinant PTH1-84 International Standard 95/646) (5) $^{55}$ are available, a validated traceable reference method for PTH1-84 is awaited. The development of tandem mass spectrometry methods for measurement of PTH offer superior specificity with similar sensitivity compared with immunoassay but they are also subject to interferences such as oxidised and phosphorylated PTH. ${ }^{27}$ In the short term, the International Federation of Clinical Chemistry and Laboratory Medicine working group for PTH is actively working towards developing assay-specific target values of PTH, with the long-term goal of establishing a reference method for PTH analysis against which other methods could be harmonised. ${ }^{56}$

It would also be of significant clinical advantage to be able to precisely recognise the relationship between changes in vitamin $\mathrm{D}$ and PTH levels. Greater understanding of the impact of relative changes in vitamin D level on PTH, rather than its absolute value, impact of factors such as age, ethnicity and calcium intake on this relationship and the time to normalisation of PTH after vitamin D level reaches a predefined target would be helpful.

Standardisation of PTH assays and information of vitamin D dynamics may help us to explain an isolated rise in PTH in a significant number of patients which in turn would allow us to focus on the subgroup of patients with a potentially progressive condition with future adverse impact on patient morbidity.

\section{Take home messages}

NPHPT is not a new entity and following its formal recognition almost a decade ago, more experience has accumulated on the diagnosis and management of this distinct endocrine condition. In clinical practice, patients are diagnosed with NPHPT either incidentally during investigation of an unrelated condition or during the assessment of patients with bone and renal involvement. There is clear evidence of significant variability in the likelihood of clinical and biochemical progression of patients with NPHPT, and this in turn makes it difficult for clinicians to make decisions on how to investigate and manage this diverse condition.

- In this review we have suggested a simple three-step pragmatic approach to a patient suspected to have NPHPT, which involves confirmation of the diagnosis, exclusion of confounding factors and finally assessment of end-organ involvement, which is the main determinant of the management plan.

\section{Handling editor Tahir S Pillay.}

Competing interests None declared.

Provenance and peer review Commissioned; externally peer reviewed.

(c) Article author(s) (or their employer(s) unless otherwise stated in the text of the article) 2018. All rights reserved. No commercial use is permitted unless otherwise expressly granted.

\section{REFERENCES}

1 Yeh MW, Ituarte $\mathrm{PH}$, Zhou HC, et al. Incidence and prevalence of primary hyperparathyroidism in a racially mixed population. J Clin Endocrinol Metab 2013:98:1122-9.

2 Rubin MR, Bilezikian JP, McMahon DJ, et al. The natural history of primary hyperparathyroidism with or without parathyroid surgery after 15 years. J Clin Endocrinol Metab 2008;93:3462-70.

3 Wills MR, Pak CY, Hammond WG, et al. Normocalcemic primary hyperparathyroidism. Am J Med 1969;47:384-91.

4 Bilezikian JP, Khan AA, Potts JT. Third International Workshop on the Management of Asymptomatic Primary Hyperthyroidism. Guidelines for the management of asymptomatic primary hyperparathyroidism: summary statement from the third international workshop. J Clin Endocrinol Metab 2009;94:335-9.

5 Cusano NE, Silverberg SJ, Bilezikian JP, et al. Normocalcemic primary hyperparathyroidism. J Clin Densitom 2013;16:33-9.

6 Lowe H, McMahon DJ, Rubin MR, et al. Normocalcemic primary hyperparathyroidism: further characterization of a new clinical phenotype. J Clin Endocrinol Metab 2007;92:3001-5

7 Eastell R, Brandi ML, Costa AG, et al. Diagnosis of asymptomatic primary hyperparathyroidism: proceedings of the Fourth International Workshop. J Clin Endocrinol Metab 2014;99:3570-9.

8 Silverberg SJ, Bilezikian JP. "Incipient" primary hyperparathyroidism: a "forme fruste" of an old disease. J Clin Endocrinol Metab 2003;88:5348-52.

9 Rao DS, Wilson RJ, Kleerekoper M, et al. Lack of biochemical progression or continuation of accelerated bone loss in mild asymptomatic primary 
hyperparathyroidism: evidence for biphasic disease course. J Clin Endocrinol Metab 1988;67:1294-8.

10 Maruani G, Hertig A, Paillard M, et al. Normocalcemic primary hyperparathyroidism evidence for a generalized target-tissue resistance to parathyroid hormone. J Clin Endocrinol Metab 2003;88:4641-8.

11 Šiprová H, Fryšák Z, Souček M. Primary hyperparathyroidism, with a focus on management of the normocalcemic form: to treat or not to treat? Endocr Pract 2016:22:294-301.

12 Wermers RA, Khosla S, Atkinson EJ, et al. Incidence of primary hyperparathyroidism in Rochester, Minnesota, 1993-2001: an update on the changing epidemiology of the disease. J Bone Miner Res 2006;21:171-7.

13 Tordjman KM, Greenman Y, Osher E, et al. Characterization of normocalcemic primary hyperparathyroidism. Am J Med 2004;117:861-3.

14 Kontogeorgos G, Trimpou P, Laine CM, et al. Normocalcaemic, vitamin D-sufficient hyperparathyroidism - high prevalence and low morbidity in the general population: A long-term follow-up study, the WHO MONICA project, Gothenburg, Sweden. Clin Endocrinol 2015:83:277-84.

15 Lundgren E, Rastad J, Thrufjell E, et al. Population-based screening for primary hyperparathyroidism with serum calcium and parathyroid hormone values in menopausal women. Surgery 1997;121:287-94.

16 Lundgren E, Hagström EG, Lundin J, et al. Primary hyperparathyroidism revisited in menopausal women with serum calcium in the upper normal range at populationbased screening 8 years ago. World J Surg 2002;26:931-6.

17 Cusano NE, Maalouf NM, Wang PY, et al. Normocalcemic hyperparathyroidism and hypoparathyroidism in two community-based nonreferral populations. I Clin Endocrinol Metab 2013:98:2734-41.

18 García-Martín A, Reyes-García R, Muñoz-Torres M. Normocalcemic primary hyperparathyroidism: one-year follow-up in one hundred postmenopausal women. Endocrine 2012;42:764-6.

19 Berger C, Langsetmo L, Hanley D, et al. Relative prevalence of normocalcemic and hypercalcemic hyperparathryoidism in a community-dwelling cohort. 33rd annual meeting of the American society of bone and mineral research. San Diego, CA, 2011. Abstract 0173

20 Martínez Díaz-Guerra G, Jódar Gimeno E, Reyes García R, et al. [Normocalcemic primary hyperparathyroidism: recommendations for management and follow-up] Endocrinol Nutr 2013;60:456.e1-456.e6.

21 Marques TF, Vasconcelos R, Diniz E, et al. Normocalcemic primary hyperparathyroidism in clinical practice: an indolent condition or a silent threat? Arq Bras Endocrinol Metabol 2011:55:314-7.

22 Nordenström E, Katzman P, Bergenfelz A. Biochemical diagnosis of primary hyperparathyroidism: analysis of the sensitivity of total and ionized calcium in combination with PTH. Clin Biochem 2011;44:849-52.

23 Calvi LM, Bushinsky DA. When is it appropriate to order an ionized calcium? J Am Soc Nephrol 2008:19:1257-60.

24 Wade TJ, Yen TW, Amin AL, et al. Surgical management of normocalcemic primary hyperparathyroidism. World I Surg 2012;36:761-6.

25 Mirzazadeh M, Morovat A, James T, et al. Point-of-care testing of electrolytes and calcium using blood gas analysers: it is time we trusted the results. Emerg Med J 2016:33:181-6

26 Crowley RK, Gittoes NJ. Elevated PTH with normal serum calcium level: a structured approach. Clin Endocrinol 2016;84:809-13.

27 Couchman L, Taylor DR, Krastins B, et al. LC-MS candidate reference methods for the harmonisation of parathyroid hormone (PTH) measurement: a review of recent developments and future considerations. Clin Chem Lab Med 2014;52:1251-63.

28 Marshall W. Association for clinical biochemistry and laboratory medicine. $2012 \mathrm{http}: / /$ www.acb.org.uk/whatwedo/science/AMALC.aspx (accessed 1 Aug 2017).

29 Bilezikian JP, Potts JT, Fuleihan G-H, et al. Summary statement from a workshop on asymptomatic primary hyperparathyroidism: a perspective for the 21st century. J Clin Endocrinol Metab 2002:87:5353-61.

30 Saleh F, Jorde R, Sundsfjord J, et al. Causes of secondary hyperparathyroidism in a healthy population: the Tromsø study. J Bone Miner Metab 2006;24:58-64.

31 Julian M-T, Olaizola I, Diaz-Soto G, et al. Diaz-Soto G, ed. Normocalcemic primary hyperparathyroidism, hyperparathyroidism, 2012. ISBN: 978-953-51-0478-0. http://www.intechopen.com/books/hyperparathyroidism/normocalcemic-primaryhyperparathyroidism

32 Fraser WD. Hyperparathyroidism. Lancet 2009:374:145-58.
33 Harvey A, Hu M, Gupta M, et al. A new, vitamin D-based, multidimensional nomogram for the diagnosis of primary hyperparathyroidism. Endocr Pract 2012;18:124-31.

34 Coe FL, Canterbury JM, Firpo JJ, et al. Evidence for secondary hyperparathyroidism in idiopathic hypercalciuria. J Clin Invest 1973:52:134-42.

35 Souberbielle JC, Cavalier E, Cormier C. How to manage an isolated elevated PTH? Ann Endocrinol 2015;76:134-41.

36 Amaral LM, Queiroz DC, Marques TF, et al. Normocalcemic versus Hypercalcemic Primary Hyperparathyroidism: More stone than bone? J Osteoporos 2012;2012:1-4.

37 Kanis JA. FRAX @ Fracture Risk Assessment Tool, 2016. https://www.sheffield.ac.uk/ FRAX/index.aspx (accessed 1 Nov 2017).

38 Rejnmark L, Vestergaard P, Brot C, et al. Increased fracture risk in normocalcemic postmenopausal women with high parathyroid hormone levels: a 16-year follow-up study. Calcif Tissue Int 2011:88:238-45.

39 Charopoulos I, Tournis S, Trovas G, et al. Effect of primary hyperparathyroidism on volumetric bone mineral density and bone geometry assessed by peripheral quantitative computed tomography in postmenopausal women. J Clin Endocrinol Metab 2006:91:1748-53.

40 Brardi S, Cevenini G, Verdacchi T, et al. Use of cinacalcet in nephrolithiasis associated with normocalcemic or hypercalcemic primary hyperparathyroidism: results of a prospective randomized pilot study. Arch Ital Urol Androl 2015;87:66-71.

41 Wermers RA, Khosla S, Atkinson EJ, et al. Survival after the diagnosis of hyperparathyroidism: a population-based study. Am J Med 1998;104:115-22.

42 Yu N, Donnan PT, Leese GP. A record linkage study of outcomes in patients with mild primary hyperparathyroidism: the Parathyroid Epidemiology and Audit Research Study (PEARS). Clin Endocrinol 2011;75:169-76.

43 Macfarlane DP, Yu N, Leese GP. Subclinical and asymptomatic parathyroid disease: implications of emerging data. Lancet Diabetes Endocrinol 2013;1:329-40.

44 Yener Ozturk F, Erol S, Canat MM, et al. Patients with normocalcemic primary hyperparathyroidism may have similar metabolic profile as hypercalcemic patients. Endocr J 2016;63:111-8.

45 Cakir I, Unluhizarci K, Tanriverdi F, et al. Investigation of insulin resistance in patients with normocalcemic primary hyperparathyroidism. Endocrine 2012;42:419-22.

46 Chen $\mathrm{G}, \mathrm{Xue} Y$, Zhang $Q$, et al. Is normocalcemic primary hyperparathyroidism harmful or harmless? J Clin Endocrinol Metab 2015:100:2420-4.

47 Bilezikian JP, Brandi ML, Eastell R, et al. Guidelines for the management of asymptomatic primary hyperparathyroidism: summary statement from the fourth international workshop. J Clin Endocrinol Metab 2014;99:3561-9.

48 Udelsman R, Åkerström G, Biagini C, et al. The surgical management of asymptomatic primary hyperparathyroidism: proceedings of the Fourth International Workshop. J Clin Endocrinol Metab 2014:99:3595-606.

49 Díaz-Soto G, Julián MT, Puig-Domingo M. Normocalcemic primary hyperparathyroidism: A newly emerging disease needing therapeutic intervention. Hormones 2012:11:390-6.

50 Grimelius L, Ejerblad S, Johansson H, et al. Parathyroid adenomas and glands in normocalcemic hyperparathyroidism - a light microscopic study. Am J Pathol 1976;83:475-82

51 Rejnmark L, Amstrup AK, Mollerup CL, et al. Further insights into the pathogenesis of primary hyperparathyroidism: a nested case-control study. J Clin Endocrinol Metab 2013:98:87-96.

52 Koumakis E, Souberbielle JC, Sarfati E, et al. Bone mineral density evolution after successful parathyroidectomy in patients with normocalcemic primary hyperparathyroidism. J Clin Endocrinol Metab 2013;98:3213-20.

53 Sankaran S, Gamble G, Bolland M, et al. Skeletal effects of interventions in mild primary hyperparathyroidism: a meta-analysis. I Clin Endocrinol Metab 2010;95:1653-62.

54 Peacock M, Bolognese MA, Borofsky $M$, et al. Cinacalcet treatment of primary hyperparathyroidism: biochemical and bone densitometric outcomes in a five-year study. J Clin Endocrinol Metab 2009:94:4860-7.

55 National Institute for Biological Standards and Control, NIBSC. WHO International standard parathyroid hormone 1-84, human recombinant, NIBSC code 95/646, version 9.0. 2010. http://www.nibsc.org/documents/ifu/95-646.pdf (accessed 1 Aug 2017).

56 Sturgeon CM, Fraser WD, Singh R, et al. Improving the comparability of parathyroid hormone measurements - a report from the IFCC working group for PTH. Biochimica Clinica 2013:37(Suppl):S431. 